\title{
Brincken, Anna-Dorothee von den, Studien zur Universalkartographie des Mittelalters
}

\section{Patrick Gautier Dalché}

\section{OpenEdition}

\section{Journals}

Édition électronique

URL : http://journals.openedition.org/ifha/2154

DOI : $10.4000 /$ ifha. 2154

ISSN : 2198-8943

\section{Éditeur}

IFRA - Institut franco-allemand (sciences historiques et sociales)

\section{Référence électronique}

Patrick Gautier Dalché, « Brincken, Anna-Dorothee von den, Studien zur Universalkartographie des Mittelalters », Revue de l'IFHA [En ligne], Date de recension, mis en ligne le 01 janvier 2010, consulté le 22 septembre 2020. URL : http://journals.openedition.org/ifha/2154 ; DOI : https://doi.org/10.4000/ ifha. 2154

Ce document a été généré automatiquement le 22 septembre 2020.

(C)IFHA 


\title{
Brincken, Anna-Dorothee von den, Studien zur Universalkartographie des Mittelalters
}

\author{
Patrick Gautier Dalché
}

Dans un fort volume accompagné d'un index et de 78 reproductions de cartes, cet ouvrage rassemble trente-huit articles présentés selon l'ordre chronologique de leur publication durant une quarantaine d'années, de 1968 à 2006.

Le titre du recueil ne rend pas un compte exact de la variété des sujets abordés. L'expression « cartographie universelle » renvoie essentiellement au genre des mappae mundi, type de cartes figurant l'orbis terrarum, soit l'œcumène. Les thèmes abordés par l'auteur semblent en réalité plus divers, car d'autres types de cartes sont examinés : cartes à zones ou à climata et cartes marines (désignées fautivement par le terme " portulan »). Plus généralement, les représentations textuelles de l'espace géographique constituent la catégorie la plus représentée, qu'elles soient liées ou non à des cartes dans les manuscrits qui les transmettent. Certaines études portent sur des mappemondes particulières. Enfin, des réalités géographiques - Europe du Nord et de l'Est - ou des collectivités ancrées dans une partie de l'œcumène - Rome, Jérusalem, chrétientés orientales - font l'objet de monographies fouillées. Étant donné la longue durée de ces représentations, leurs sources antiques et leurs prolongements à l'époque moderne, le champ chronologique est largement ouvert jusqu'à Mercator.

A.-D.v.d.B. est une spécialiste reconnue de la cartographie médiévale. Elle a marqué l'étude des représentations géographiques par deux articles pionniers (1968 et 1970) qui affirmaient avec force une relation jusque-là peu aperçue entre chronique universelle et mappa mundi. Loin de la stigmatisation courante de ces dernières comme pure régression par rapport à la " science " antique, et loin des généralités sur l'imaginaire médiéval, elle a montré qu'elles avaient pour fonction la mise en scène de l'histoire du salut, associant ainsi temps et espace dans une continuité signifiante. Elle s'est aussi intéressée à la matérialité des cartes, à l'écriture de leurs légendes et aux signes par lesquels elles montrent les objets représentés. 
Du point de vue de la problématique, ces articles sont d'excellents témoins d'un état de l'historiographie. Par là, ils invitent à poursuivre la recherche en s'interrogeant sur la valeur heuristique des postulats qu'ils illustrent : opposition entre Moyen Âge et « renaissance ptoléméenne » des XVe-XVIe siècles, entre " tradition » et "modernité "; caractère « correct » ou non des représentations cartographiques; absence de rapport des mappae mundi à la " pratique ». L'auteur ne dédaigne pas non plus de recourir à des essences qui semblent valoir explication, comme cette phrase à propos de l'ornementation des mappae mundi : « les Arabes (sic) sont plus proches de la réalité, les Occidentaux plus artistes et plus individuels » (p. 135).

Ainsi qu'il est noté en introduction, ces travaux répondant à des sollicitations extérieures, colloques ou volumes de mélanges, ne visent nullement à procurer une vue systématique. La plupart juxtaposent avec une extrême minutie, selon un ordre chronologique ou thématique, la description des œuvres liées au thème abordé. Les mêmes données y sont souvent répétées jusque dans le détail, et les mêmes objets réapparaissent à de nombreuses reprises. De ce point de vue, la lecture continue peut procurer au lecteur profane une vue précise et utile de la plupart des documents connus, ainsi que de quelques inédits.

Patrick Gautier Dalché (CNRS/ EPHE) 